\title{
Role of Bedside Sonography in Detecting Rib Fractures and Related Injuries
}

\author{
(1) Hassan Amiri ${ }^{1}$, (1) Niloofar Ghodrati ${ }^{2}$, (1) Tayeb Ramim ${ }^{3}$, (1) Ali Ghorban ${ }^{1}$, (1) Samad Shams-Vahdati ${ }^{4}$, \\ (1) Mehran Jalilzadeh Binazar 5
}

1Department of Emergency Medicine, Iran University of Medical Sciences, Tehran, Iran

2Department of Emergency Medicine, Alborz University of Medical Sciences, Karaj, Iran

3 Sina Trauma and Surgery Research Center, Tehran University of Medical Science, Tehran, Iran

${ }^{4}$ Department of Emergency Medicine, Road Traffic Injury Research Center, Tabriz University of Medical Sciences, Tabriz, Iran

${ }^{5}$ Road Traffic Injury Research Center, Tabriz University of Medical Sciences, Tabriz, Iran

\begin{abstract}
Aim: About $40 \%$ of patients with trauma, experience chest related injuries. Rib fracture remains the most frequent finding in chest trauma. Some literatures have suggested chest wall ultrasonography as a potential replacement for chest X-ray (CXR) in detecting rib fractures. The aim of this study is to assess sensitivity and specificity of bedside ultrasonography in detecting rib fractures and related injuries.

Materials and Methods: Patients between April 2012 and April 2014 were enrolled in our prospective cross-sectional study. Then emergency medicine specialists performed a bedside ultrasonography to detect any probable fracture and suspected injuries. We took CXRs and an expert radiologist looked for fracture and related injuries. A chest computerized tomography scan was taken and compared with findings of CXR and ultrasonography.

Results: Out of 360 patients, 238 met our inclusion criteria and enrolled in the study; where 222 (93.3\%) were male and 16 (6.7\%) were female with the average age of $33.78 \pm 11.62$ ( \pm standard deviation). The sensitivity and specificity of two modalities in detecting fracture, pneumothorax, hemothorax and contusion were analyzed.

Conclusion: Our study showed that bedside ultrasonography could substitute CXR in detecting not only rib fractures but also related comorbidities especially in minor trauma.
\end{abstract}

Keywords: Rib fracture, bedside ultrasonography, injuries, emergency physician, sensitivity, chest X-ray

\section{Introduction}

About $40 \%$ of patients with trauma experience chest related injuries. External forces including motor vehicle collisions and falling from height, considered as the most common causes of the blunt trauma $(1,2)$. Rib fracture remains the most frequent finding in chest trauma and occurs because of the blunt trauma in almost half of the cases (3). Rib fractures happen while direct force applied to the sternum caused by a motor vehicle. Aging increases likelihood of rib fractures. Higher thoracic flexibility of children reduces the risk of fracture (1-3).
Due to semi-protected position of the upper ribs $\left(1^{\text {st }}\right.$ to $\left.3^{\text {rd }}\right)$ and limited range of motion of the lower ribs $\left(9^{\text {th }}\right.$ to $\left.12^{\text {th }}\right)$, these ribs are less vulnerable to the trauma. Therefore, $4^{\text {th }}$ to $9^{\text {th }}$ ribs fracture more frequently. However, upper rib fractures, accompany higher mortality rate due to comorbid subclavian artery or vein injuries; and lower rib fractures can increase three and four times the rupture probability of the liver and spleen, respectively (4-7). The more the ribs fracture, the higher the comorbidities occur. Patients with three or more fractured ribs require hospitalization for pain alleviation and further investigations $(8,9)$. 
Chest X-ray (CXR) remains a beneficial and sensitive tool in detecting rib fractures.

Bony construction and oblique view of ribs in a CXR make it easy to detect fractures (10-13).

Some literatures have suggested chest wall ultrasonography as a potential replacement for CXR in detecting rib fractures especially in trauma related ones. Moreover, chest wall ultrasonography can differentiate traumatic fractures from pathologic ones (1421).

A few studies have evaluated the role of ultrasonography in finding fracture of the ribs; however, in none of them emergency physicians have used bedside ultrasonography at emergency departments (22-25). Moreover, small sample size in previous studies made it crucial to perform a study with a larger sample size.

The aim of this study is to assess sensitivity and specificity of bedside ultrasonography in detecting rib fractures and related injuries including pneumothorax, hemothorax and pulmonary contusion.

\section{Materials and Methods}

\section{Study Design}

Patients who were referred to our tertiary emergency department between April 2012 and April 2014 were enrolled in our prospective cross-sectional study. We included all stable patients with chest trauma who were older than 10 years (being cooperative in localizing pain), fully conscious (Glasgow coma scale=15) and without distracting pain (difficulty in pain localization). After approval of ethics committee, we took written consent form from all patients who were enrolled in the study.

We excluded patients if either they face life-threatening condition or experience decrease in GCS. We also excluded patients without rib fractures, patients who have more than 3 fractures and patients with massive emphysema.

The patients were asked to localize the most excruciating area. Then emergency medicine specialists performed a bedside ultrasonography, using a Medison- $X$ (South Korea) with a linear 7.5-10 $\mathrm{mHz}$ probe, for the localized area and surroundings in a sitting position. This was used to detect any probable fracture and suspected injuries such as: Pneumothorax, hemothorax and soft tissue contusion. We used following criteria in detecting probable fracture: Cortical discontinuity, acoustic shadow following fracture, reverberation artifact, and local hematoma.

We took anteroposterior (AP) and lateral CXRs after stabilization of patients. An expert radiologist who was unaware of the study looked for the fracture and related injuries. A chest computerized tomography (CT) scan (64-multislice), as the gold standard, was taken and compared with findings of CXR and ultrasonography.

\section{Data Analysis}

We used SPSS-15.0 to calculated sensitivity and specificity of CXR and ultrasonography for detection of fracture, hemothorax, pneumothorax, and contusion.

\section{Ethical Considerations}

Ethics Committee of Iran University of Medical Sciences approved the study before patients' enrollment (approval number: 91/D/131/965).

\section{Results}

Out of 360 patients, 238 met our inclusion criteria and enrolled in the study; where 222 (93.3\%) were male and 16 (6.7\%) were female with the average age of $33.78 \pm 11.62$ ( \pm standard deviation).

Motor vehicle collisions were the most frequent cause of trauma in $171(71.8 \%)$ patients.

Figure 1 shows the incidence of fractures detected by CXR, ultrasonography and CT. Incidence of pneumothorax, hemothorax and contusion based on diagnostic modality is shown in Table 1.

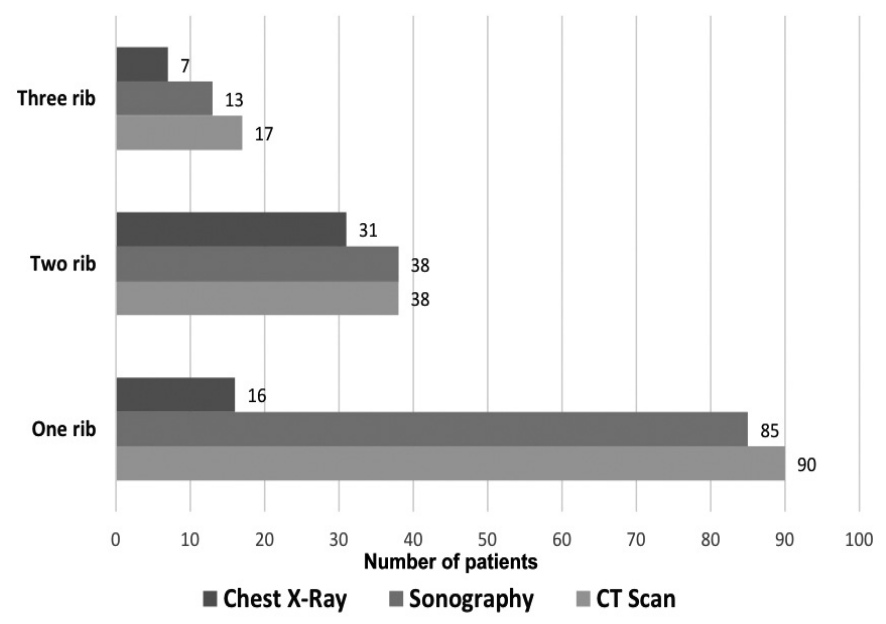

Figure 1. Incidence of fractures detected by chest X-ray, ultrasonography and computerized tomography

CT: Computerized tomography

Table 1. Incidence of injuries based on diagnostic modality

\begin{tabular}{|c|c|c|c|}
\hline & \multicolumn{3}{|c|}{ Modality } \\
\hline & CXR & Ultrasonography & $\mathrm{CT}$ \\
\hline Hemothorax (n) & 0 & 17 & 28 \\
\hline Pneumothorax (n) & 7 & 54 & 58 \\
\hline Contusion (n) & 0 & 3 & 18 \\
\hline
\end{tabular}

CXR: Chest X-ray, CT: Computerized tomography 
Table 2. Sensitivity and specificity of injuries detected on chest $\mathrm{X}$-ray and ultrasonography

\begin{tabular}{llll}
\hline & Findings & Sensitivity \% & Specificity \% \\
\hline \multirow{4}{*}{ CXR $(n=238)$} & Fracture & 37.2 & 100 \\
\cline { 2 - 4 } & Hemothorax & 0 & 100 \\
\cline { 2 - 4 } & Pneumothorax & 12.1 & 100 \\
\cline { 2 - 4 } & Contusion & 0 & 100 \\
\hline \multirow{3}{*}{$\begin{array}{l}\text { Ultrasonography } \\
\text { (n=238) }\end{array}$} & Fracture & 93.8 & 100 \\
\cline { 2 - 4 } & Hemothorax & 60.7 & 100 \\
\cline { 2 - 4 } & Pneumothorax & 93.1 & 100 \\
\cline { 2 - 4 } & Contusion & 16.7 & 100 \\
\hline CX: Chest X-ray & & & \\
\hline
\end{tabular}

In addition, the sensitivity and specificity of two modalities in detecting fracture, pneumothorax, hemothorax and contusion were depicted in Table 2.

\section{Discussion}

In the case of thoracic injuries, when physicians suspect fracture or related injuries, they use various imaging modalities such as: AP and lateral CXR, chest ultrasonography and chest CT scan.

Majority of patients in our study were young male people who were referred due to a motor vehicle collision. Most of the detected fractures with CXR were fracture of two ribs, however one rib fractures were the mostly detected ones using CT scan and bedside ultrasonography. This indicates more diagnostic value of CXR in more severe trauma. On the other hand, in less severe trauma usage of ultrasonography or CT is more diagnostic. Higher sensitivity rate of ultrasonography in comparison with CXR (93.8\% to 37.2\%) in detecting fractures denotes superiority of ultrasonography usage.

Moreover, better results in detecting injuries suggest advantage of ultrasonography comparing with CXR. Nonetheless, low sensitivity rates for detection of contusion (16.7\%) and hemothorax (60.7\%) make the usage of CT scan inevitable in suspected patients.

Turk et al. (22) studied 20 patients with normal CXR. They performed ultrasonography and found rib fractures in 18 of 20 patients. Kara et al. (24) evaluated 36 patients with chest trauma who had no fracture in their CXRs. Surprisingly, 15 of the patients had rib fractures.

If we consider minor trauma as a cause of these biases, ultrasonography can significantly detect less severe trauma.

Griffith et al. (26) assessed 50 patients with both CXR and ultrasonography. The findings are as follows: 8 fractures in 6 patients detected by CXR in comparison with 83 fractures in 39 patients detected by ultrasonography, where 4 of 83 fractures were in costochondral junction and 5 of them were costal fractures in cartilages.

\section{Study Limitations}

Different level of experience in performing ultrasonography was one of our study's limitations, which several one-day workshops were held to minimize the dissimilarity.

Low injury severity was another limitation of our study. It is unclear what impact, if any, multiple fractures on the same rib or adjacent ribs would have on the sensitivity of this mode. We also excluded patients with emphysema. Subcutaneous emphysema can lead to a poor sonographic view.

\section{Conclusion}

Our study showed that bedside ultrasonography could substitute CXR in detecting not only rib fractures but also related comorbidities. Moreover, higher sensitivity in fractures with less severe trauma makes ultrasonography a valuable screening method in survey of patients injured with minor trauma.

\section{Ethics}

Ethics Committee Approval: Iran University of Medical Sceinces, (approval number: 91/D/131/965).

Informed Consent: After approval of ethics committee, we took written consent form from all patients who were enrolled in the study.

Peer-review: Externally peer-reviewed.

\section{Authorship Contributions}

Surgical and Medical Practices: A.G., N.G., Concept: H.A., T.R, S.S.V., Design: H.A., N.G., S.S.V., Data Collection or Processing: A.G., T.R., Analysis or Interpretation: A.G., Literature Search: A.G., M.J.B., Writing: M.J.B.

Conflict of Interest: No conflict of interest was declared by the authors.

Financial Disclosure: The authors declared that this study received no financial support.

\section{References}

1. Khandhar SJ, Johnson SB, Calhoon JH. Overview of thoracic trauma in the United States. Thorac Surg Clin. 2007;17:1-9.

2. Eckstein, M, Henderson S. Thoracic Tr. In: Rosen's Emergency Medicine: Concepts and Clinical Practice, 6th edition, Marx, JA, Hockberger, RS, Walls, RM (Eds), Mosby Elsevier, Philadelphia 2006.

3. Love JC, Symes SA. Understanding rib fracture patterns: incomplete and buckle fractures. J Forensic Sci. 2004;49:1153. 
4. Shweiki E, Klena J, Wood GC, Indeck M. Assessing the true risk of abdominal solid organ injury in hospitalized rib fracture patients. J Trauma. 2001;48:684.

5. Bergeron E, Lavoie A, Clas D, Moore L, Ratte S, Tetreault S, et al. Elderly trauma patients with rib fractures are at greater risk of death and pneumonia. J Trauma. 2003;54:478.

6. Holcomb JB, McMullin NR, Kozar RA, Lygas MH, Moore FA. Morbidity from rib fractures increases after age 45. J Am Coll Surg. 2003;196:549-55.

7. Brasel KJ, Guse CE, Layde P, Weigelt JA. Rib fractures: Relationship with pneumonia and mortality. Crit Care Med. 2006;34:1642-6.

8. Traub M, Stevenson M, McEvoy S, Briggs G, Lo SK, Leibman S, et al. The use of chest computed tomography versus chest $\mathrm{x}$-ray in patients with major blunt trauma. Injury. 2007;38:43-7.

9. Sirmali M, Turut H, Topcu S, Gülhan E, Yazici U, Kaya S, et al. A comprehensive analysis of traumatic rib fractures: Morbidity, mortality and management. Eur J Cardiothorac Surg. 2003;24:133-8.

10. Bergeron E, Lavoie A, Clas D, Moore L, Ratte S, Tetreault S, et al. Elderly trauma patients with rib fractures are at greater risk of death and pneumonia. J Trauma 2003;54:478-85.

11. Holcomb JB, McMullin NR, Kozar RA, Lygas MH, Moore FA. Morbidity from rib fractures increases after age 45. J Am Coll Surg. 2003;196:549-55.

12. Livingston DH, Shogan B, John P, Lavery RF. CT diagnosis of Rib fractures and the prediction of acute respiratory failure. J Trauma 2008;64:905-11.

13. Holmes JF, Ngyuen H, Jacoby RC, McGahan JP, Bozorgchami H, Wisner DH. Do all patients with left costal margin injuries require radiographic evaluation for intra abdominal injury? Ann Emerg Med. 2005;46:232-6.

14. Hurley ME, Keye GD, Hamilton S. Is ultrasound really helpful in the detection of rib fractures? Injury. 2004;35:562-6.

15. Kara M, Dikmen E, Erdal HH, Simsir I, Kara SA. Disclosure of unnoticed rib fractures with the use of ultraultrasonography in minor blunt chest trauma. Eur J Cardiothorac Surg. 2003;24:608-13.
16. Rainer TH, Griffith JF, Lam E, Lam PK, Metreweli C. Comparison of thoracic ultrasound, clinical acumen, and radiography in patients with minor chest injury. J Trauma. 2004;56:1211-3.

17. Chan SS. Emergency bedside ultrasound for the diagnosis of rib fractures. Am J Emerg. 2009;27:617-20.

18. Reissig A, Copetti R, Kroegel C. Current role of emergency ultrasound of the chest. Crit Care Med. 2011;39:839-45.

19. Paik SH, Chung MJ, Park JS, Goo JM, Im JG. High-resolution ultrasonography of the rib: can fracture and metastasis be differentiated? AJR Am J Roentgenol. 2005;184:969-74.

20. Gupta A, Jamshidi M, Rubin JR. Traumatic first rib fracture: is angiography necessary? A review of 730 cases. Cardiovasc Surg. 1997;5:48-53.

21. Koh DM, Burke S, Davies N, Padley SP. Transthoracic US of the chest: clinical uses and applications. Radiographics. 2002;22:e1.

22. Turk F, Kurt AB, Salgam S. Evaluation by ultrasond of traumatic rib fractures missed by radiography. Emerg Radiol. 2010;17:473-7.

23. Hurley ME, Keye GD, Hamilton S. Is ultrasound realy helpful in the detection of rib fractures?. Int J Care Injured. 2004;35:562-6.

24. Kara M, Dikmen E, Erdal HH, Simsir I, Kara SA. Disclosure of unnoticed rib fracture with the use of ultraultrasonography in minor blunt chest trauma. Eur J Cardiothorac Surg. 2003;24:608-13.

25. Malghem J, Vande Berg BC, Lecouvet FE, Maldague BE. Costal cartilage fracture as revealed on CT and ultrasonography. Ame J of Radilogy. 2001;176:429-32.

26. Griffith JF, Rainer TH, Ching ASC, Law KL, Cocks RA, Metreweli C. Ultrasonography compared with radiography in revealing acute rib fracture. AJR Am J Roentgenol. 1999;173:1603-9. 